\title{
LIFE-THREATENING TRACHEOSTOMY SITE BLEEDING FROM GRANULATION TISSUE MIMICKING TRACHEO-INNOMINATE FISTULA
}

\author{
Paudel $S^{1}$, Ranabhat $K^{2}$, Devkota $U^{3}$
}

${ }^{1}$ Otorhinolaryngology and Head and Neck Surgery, ${ }^{2}$ Radiology, ${ }^{3}$ Neurosurgery, Upendra Devkota Memorial National

Institute of Neurological and Allied Sciences, Bansbari, Kathmandu, Nepal

\begin{abstract}
Tracheostomy is a common life- saving procedure carried out for variety of indications. Of the various complications, profuse stomal bleeding could either be due to granulation tissues or major vessel fistula. We report one such case where there was repeated profuse bleeding mimicking tracheoinnominate fistula. A preliminary CT-angiogram was done, that ruled out fistula and it was safely tackled by bipolar diathermy in the operating theater. Had it been the alternative diagnosis it would definitely require a vascular surgeon. Thus CT-angiogram could be a useful investigation to pin down the cause and appropriate management
\end{abstract}

\section{KEYWORDS}

CT- angiogram, granulation tissue, tracheo-innominate fistula

\section{CORRESPONDING AUTHOR}

Dr. Sangya Paudel,

Otorhinolaryngology - Head and Neck Surgery,

Upendra Devkota Memorial National Institute

of Neurological and Allied Sciences, Bansbari,

Kathmandu, Nepal

Email: sangyapaudel456@gmail.com 


\section{INTRODUCTION}

Tracheostomy is a common procedure in intensive care units for patients who require prolonged ventilation for the prevention of tracheal stenosis and pulmonary toileting. Tracheostomy can be associated with serious complications as tracheal stenosis, increased bacterial colonization around the stoma and rarely fatal hemorrhage due to various causes. ${ }^{1,2}$

We present a rare case of hemorrhage post tracheostomy hemorrhage which occurred on the 17th postoperative day.

\section{CASE REPORT}

A 45 year old male was brought to our emergency department after a road traffic accident. He was diagnosed as a case of bilateral frontal contusion and left cerebellar hematoma. He underwent bifrontal decompressive craniectomy with contusectomy and evacuation of posterior fossa epidural hematoma. Anticipating prolonged intubation early tracheostomy was done on the 1st postoperative day. The tracheostomy tube was changed twice on the 7th and 13th postoperative days uneventfully.

On the 17th day following tracheostomy, the patient developed acute onset bleeding from the tracheostomy site. The tracheostomy tube was fully inflated immediately and the site was packed with adrenalin soaked gauge till bleeding stopped. The patient was then resuscitated with crystalloids.

On the following day, the patient had more severe bleeding, from the tracheostomy site, oral and nasal cavities. Clearing of all collected blood was done tracheostomy site was packed with adrenalin pack and the patient was immediately taken for CTAngiogram to rule out the dreaded complication of tracheo-innominate fistula (TIF).

CT-angiogram did not reveal TIF, instead granulation tissues were seen around the tracheal stoma. The patient was taken to the operating room, endotracheal intubation was done followed by complete removal of blood and clots to prevent aspiration and exploration of the tracheostomy site. During exploration, granulation tissue was seen around isthmus of the thyroid gland and tracheal stoma. There was active bleeding from these regions. Cauterization of bleeding points was done with bipolar electrocautery; operative site was thoroughly washed with normal saline mixed with a hydrogen peroxide solution. Active bleeding then stopped and the endotracheal tube was replaced by tracheostomy tube and the stoma was packed with ribbon gauge soaked in adrenalin and oxymetazoline solution. The patient was then shifted to ICU for mechanical ventilation and was kept under antibiotic coverage. Evaluation of the pack was done on the next day. There was no active bleeding; hence the pack was removed after 48 hours. On the 7th day of exploration, tracheostomy tube was changed without any difficulty and bleeding.

\section{DISCUSSION}

Tracheostomy complications range from minor bleeding to life-threatening airway obstructions. It can be categorized as early or late. ${ }^{3}$ Early complications are those occurring within the first week of tracheostomy and beyond that period is late. In an open surgical technique, stomal infection and bleeding are the most common complications. ${ }^{3,4}$ Bleeding following tracheostomy tube placement is seen in 5.7\% of cases. ${ }^{5}$ Granulation tissue formation around the tracheal stoma has been considered as a complication of long-term tracheostomy. ${ }^{6}$ Granulation tissue results due to stomal infection causing necrosis of mucosa and cartilage then abnormal healing of injured airway mucosa. It occurs during the first stage of a healing process. ${ }^{7,8}$ The tissue contains fibrous connective tissue and new blood vessels are formed several days after trauma. Because of angiogenesis granulation tissue can bleed easily. ${ }^{7,8}$

TIF isanuncommonandlife-threatening complication of tracheostomy with a reported incidence of $0.7 \% .{ }^{9,10}$ It occurs due to pressure necrosis of the anterior tracheal wall; tracheostomy cuff or tip causes erosion of the trachea and innominate artery. ${ }^{11}$ As the entire tracheal tree is filled with blood, it is very difficult to do bronchoscopic examination during the time of acute bleeding. ${ }^{12}$ An oblique digital subtraction view of a selective innominate arterial injection had the highest diagnostic value, although there are not enough data to assess the sensitivity and specificity of this diagnostic method..$^{12}$ Management in these two cases is entirely different, TIF should be managed by Cardio Thoracic Vascular Surgeon whereas granulation tissue can be managed by Head and Neck Surgeon.

In this case, granulation tissue can be seen in various sections with increased uptake of contrast. Also, an image of intact vessel prevented further invasive procedure for diagnosis and treatment.

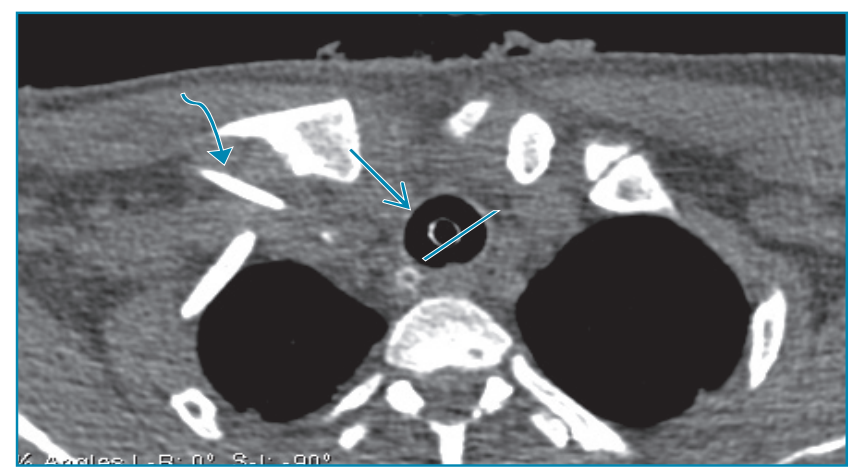

Fig. 1: Non-contrast CT of the neck shows tracheostomy tube (straight thin arrow) with the balloon inflated in situ and overlying subcutaneous emphysema. No hyperdense areas suggestive of acute

hemorrhage is noted. Posterior and towards the right is a nasogastric tube in the esophagus (straight line) and on the right is central venous access in the subclavian vein (curved arrow). 


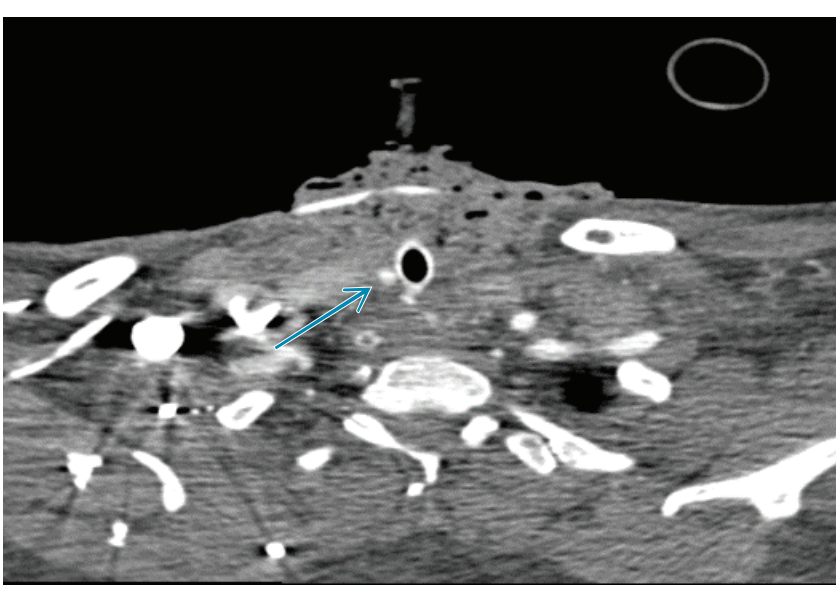

Fig. 2: Post-contrast axial image cephalad to the previous image shows a section of tracheal tube as it enters the trachea. Small discrete foci (at least three) of avid contrast enhancement are seen on soft tissue posterior and right posterolateral aspect of the tracheostomy tube (straight arrow). This is in the tracheal wall around the tracheostomy tube.

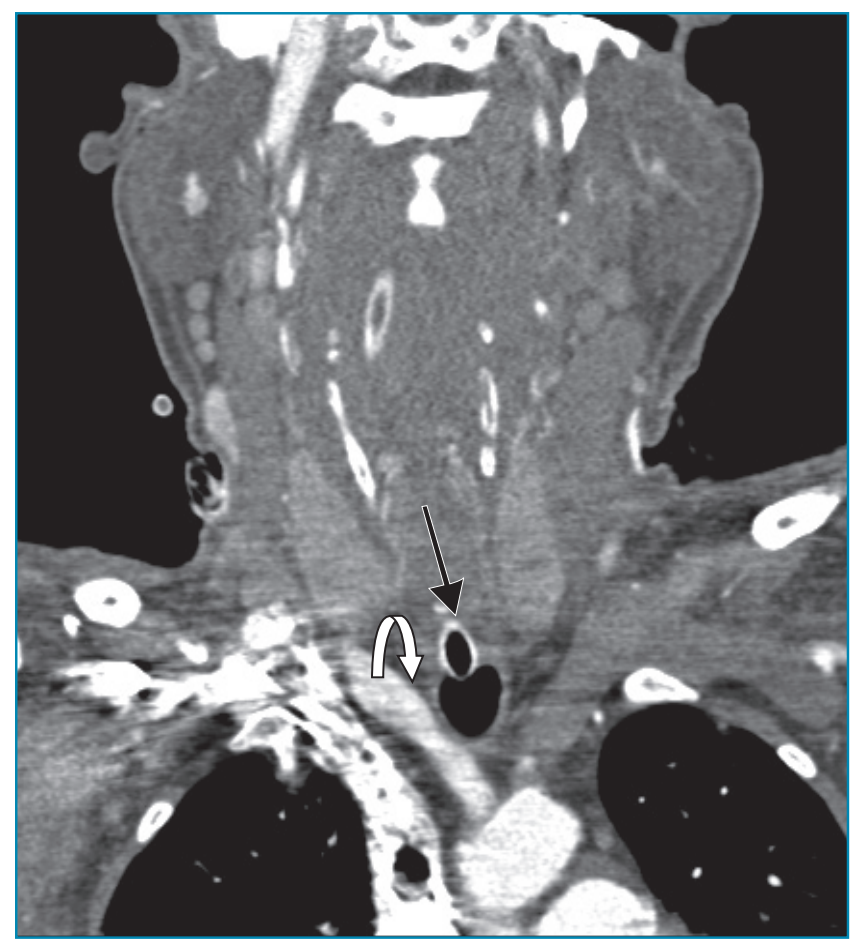

Fig. 3: Coronal reformation images at the level of the tracheal tube again show inflated balloon (straight arrow) inside the trachea passing in close approximation to the innominate artery on the right (curved arrow). No fistulous communication is seen between the trachea and the surrounding artery. No extravasation of contrast into the trachea/ tracheostomy tube is seen. Small contrast enhancing focus seen in the superior aspect of the tracheal tube section corresponds to the focus seen on the axial images.

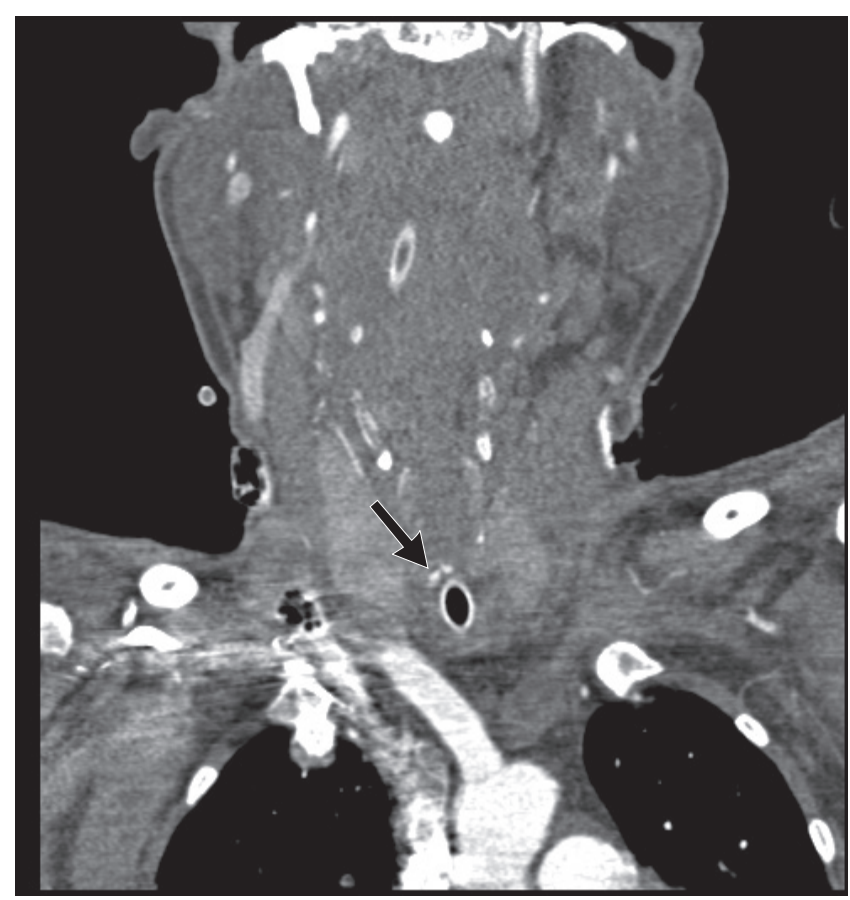

Fig. 4: Coronal section slightly anterior to the previous one shows more contrast-enhanced foci in the tracheal wall superior aspect of the tracheal tube.

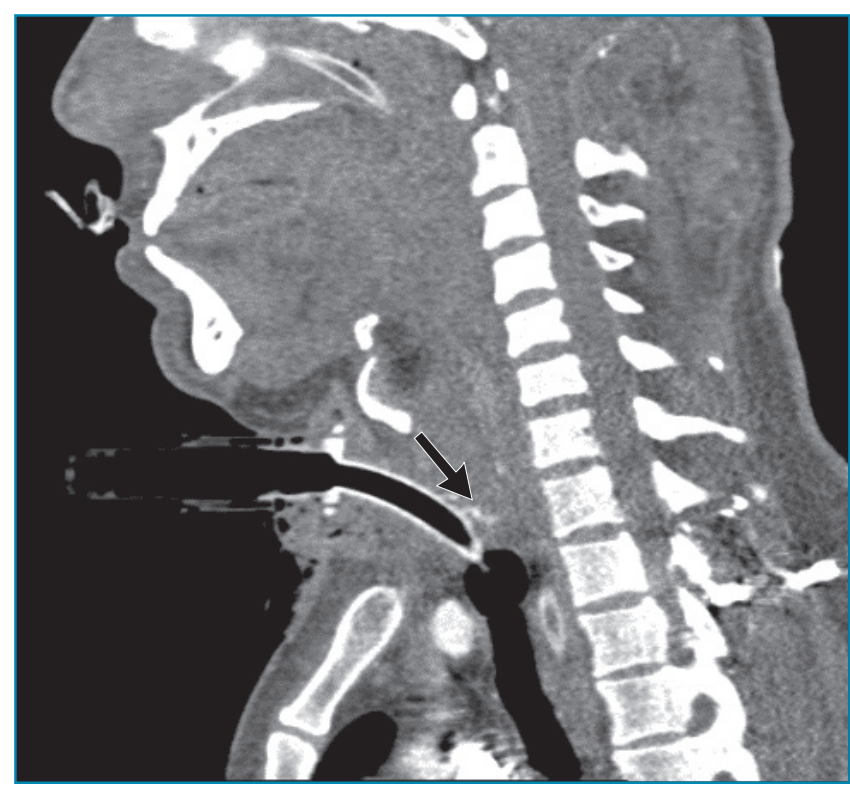

Fig. 5: Sagittal images at the level of the trachea again show tracheostomy tube with an inflated balloon in the trachea. Cross section of the Innominate artery is seen anterior to the trachea and nasogastric tube is seen posteriorly in the esophagus. Contrast enhancing foci (straight arrow) is seen posterior to the tracheal tube superiorly in the tracheal soft tissue.

To prevent the formation of granulation tissues we should avoid excess mechanical irritation, use proper sized tube; swivel apparatus and ventilator tubing support. Prevention of stomal infection is important because infection may impair tissue healing. Meticulous care of stoma should be done for prevention of bacterial contamination. ${ }^{13}$ 
Along with bleeding from tracheostomy site, airway granulations can also cause tracheal stenosis. Brendan et al reported 3 cases of tracheal granulation tissue after percutaneous tracheostomy treated with ND-Yag Laser which presented as bleeding from tracheostomy site and airway obstruction. ${ }^{14}$

In the patient presented here, tracheal granulation tissue formation occurred superior to the point of entry of the tracheostomy tube into the trachea. This appears to be a less commonly reported site of posttracheostomy intraluminal tracheal lesions than infra-stomally. ${ }^{15}$ In our case there was no airway obstruction but granulation presented as massive hemorrhage which was managed successfully by exploration cauterization and packing.

Profuse bleeding from stoma could be either due to granulations tissue or major vessel fistula. Tracheoinnominate fistula will require the expertise of Vascular Surgeon to deal with whereas granulation tissue can be dealt with by Head and Neck Surgeon. CT-Angiogram can differentiate the two conditions, therefore could be extremely helpful.

\section{REFERENCES:}

1. Zeitouni AG, Kost KM: Tracheostomy a retrospective review of 281 cases. J Otolaryngol 1994; 23: 61-66

2. Stock MC, Wood Ward CG, Shapiro BA, Cane RD, Lewis V, Pecaro B: Perioperative complications of elective tracheostomy in critically ill patient. Crit Care Med 1086; 14: 861-863.

3. Sebastian Fernandez, Bob Mahajan, Erik Folch, Ivan Caviedes, Jorge Guerrero, Adnan Majid: Tracheostomy tube placement early and late complications. J Bronchol Intervent Pulmonol 2015; 22: 357-364.

4. Oliver ER, Gist A, Gillespie MB. Percutaneous dilatational tracheostomy versus surgical tracheostomy: an updated metaanlysis. Laryngosope 2007; 117: 1570-1575.

5. Delaney A, Bagshaw SM, Nalos M: Percutaneous dilational tracheostomy versus surgical tracheostomy in critically ill patient: a systemic review and metaanalysis. Crit Care 2006; 10: R55.

6. Law JH, Barnhart K, Rowlett W, de la Rocha O, Lowenberg S. Increased frequency of obstructive airway abnormalities with long-term tracheostomy. Chest 1993; 104: 136-8

7. Santos OM, A Frassiabi A, Weymuller JrEA: Risk factor associated with prolonged intubation and laryngeal injury. Otolaryngol Head Neck Surg 1994; 115: 453-9.

8. Priyanka G Patil, Ravi Jain, Soumi M Chaudhari, JM Thakkar, BM Patel. Tracheal granuloma as an incidental finding during endotracheal intubation. Guj Med J 2012; 67: 123-5.
9. Hamaguchi S, Nakajima Y. Two cases of tracheoinnominate artery fistula following tracheostomy treated successfully by endovascular embolization of the innominate artery. J Vasc Surg 2012; 55: 545-7.

10. Scalise P, Prunk SR, Healy D, Votto J. The incidence of tracheoarterial fistula in patients with chronic tracheostomy tubes : a retrospective study of 544 patients in a long-term care facility. Chest 2005; 128: 3906-9.

11. Sung JH, Kim IS, Yang SH, Hong JT, Son BC, Lee SW. Is computerized tomography angiographic surveillance valuable for prevention of tracheoinnominate artery fistula, a life-threatening complication after tracheostomy? J Korean Neurosurg Soc 2011; 49: 107-11.

12. Yang FY, Criado E, Schwartz JA, Keagy BA, Wilcox BR. Trachea-innominate artery fistula : retrospective comparison of treatment methods. South Med J 1988; 81: 701-6.

13. Sasaki CT, Horiuchi M, Koss N. tracheostomy realted subglottic stenosis: Bacteriologic pathogenesis. Laryngoscope 1967; 89: 857-65.

14. Madden BP, Datta S, McAnulty G: Tracheal Granulation tissue after percutaneous tracheostomy treated with Nd-Yag laser: Three cases. J laryngol Otol 2001; 115: 743-4.

15. Arola MK, Inberg MV, Puhakka H. Tracheal stenosis after tracheostomy and after orotracheal cuffed intubation. Acta Chir Scand 1981; 147: 183-92. 